\title{
Gas gangrene infection of the eyes and orbits
}

\author{
GERARD W CROCK, ' WILSON J HERIOT, ' PATTABIRAMAN JANAKIRAMAN,' \\ AND JOHN M WEINER?
}

From the 'Department of Ophthalmology, University of Melbourne, and the ${ }^{2} \mathrm{C}$ H Greer Pathology Laboratory, the Royal Victorian Eye and Ear Hospital, East Melbourne, Australia

SUMmary The literature on Clostridium perfringens infections is reviewed up to 1983. An additional case is reported with bilateral clostridial infections of the eye and orbit. One eye followed the classical course of relentless panophthalmitis, amaurosis, and orbital cellulitis ending in enucleation. The second eye contained intracameral mud and gas bubbles that were removed by vitrectomy instrumentation. Subsequent removal of the toxic cataract resulted in a final aided visual acuity of $6 / 18, N 8$. This is the third report of a retained globe, and we believe the only known case where the patient was left with useful vision.

Clostridium perfringens is a ubiquitous Grampositive bacillus found in soil and bowel flora. It is the most common of four clostridia species identified in cases of gas gangrene in man. ' All species are obligate anaerobes and are usually saprophytic rather than pathogenic. Clostridium perfringens is a feared contaminant of limb injuries and may result in death due to the effects of its powerful exotoxins, which include lecithinase, phospholipase, neuraminidase, cytolysin, collegenase, and DNA-ase. ${ }^{2}$

Despite the potential frequency of contamination intraocular infection is rare. When the infection is established, however, the outcome has been loss of the globe in almost every case. Systemic toxicity has been reported rarely, perhaps because established panophthalmitis has been almost uniformly treated by surgical removal of the globe or orbital contents. Our recent experience from a case with bilateral ocular and orbital involvement confirms the sinister nature of such an infection but, for the first time, provides evidence that curative measures are now available.

\section{Case report}

A 38-year-old male construction worker struck a stick of gelignite with a pick while digging a trench on 28 August 1982 . In the explosion that followed he suffered extensive superficial injuries to the face,

Correspondence to Professor G W Crock, University of Mclbourne, Department of Ophthalmology, Royal Victorian Eyc and Ear Hospital, 32 Gisborne Strect, East Melbourne, Victoria 3002, Australia. arms, chest, and abdomen. He was admitted to a general hospital, where he was examined under anaesthesia, and his injuries were attended to.

Ocular findings. The right cornea and anterior chamber were intact. There was a scleral laceration over the superonasal area of the pars plana with vitreous prolapse. Pieces of stone were seen in the vitreous, and there was commotio retinae. An attempt was made to remove the foreign bodies with Sutherland forceps. This was unsuccessful, and the scleral wound was closed.

In the left eye there was a corneal perforation nasally with a tear in the underlying iris. Mud and other debris were present in the anterior chamber particularly in the inferior angle. The corneal wound was sutured with 10/0 monofilament nylon. After closure of the corneal wound two ports (nasal and temporal) were made inside the limbus, but it was not possible to clear the anterior chamber with Sutherland forceps. The facial wounds were cleared out, and subconjunctival injections of gentamycin and cephalosporin were given. Parenteral therapy was also started with these same antibiotics. The patient was transferred to the Royal Victorian Eye and Ear Hospital on 29 August 1982 and taken straight to the operating theatre.

Operative findings 29 August 1982. The right eye showed diffuse corneal oedema, and multiple granular particles of dirt were embedded in the stroma. There was a total hypopyon. A vitreous biopsy was taken through the pars plana (single port) with the Intra Ocular Cutter (IOC) Micro-Fine, Australia. The aspirate was greyish-brown and fluid 
in consistency. Filtered air was injected into the eye together with $8 \mu \mathrm{g}$ of gentamycin. There was gross oedema of both lids with multiple embedded foreign bodies.

On the left side the lids were similarly swollen and impregnated with foreign materials. There were full thickness wounds in the superotemporal and inferotemporal regions that extended deep into the orbit. These tracks were filled with greyish pus and debris. They were irrigated and rubber drains were inserted. The left cornea was impregnated with small quartz and other particles of earth. There was an abscess around the perforation site and generalised corneal oedema. A small gas bubble was evident in the anterior chamber that contained mud, quartz particles, and hypopyon.

The anterior chamber was cleared through two limbal ports with the IOC. The mud was enmeshed in a dense fibrin layer all of which came away en masse from the anterior surface of the iris after infusion aspiration. Streptomycin $(250 \mathrm{mg})$ was injected subconjunctivally.

At dressing on 30 August there was a purulent discharge from the right eye. The cornea was completely hazy. There was marked proptosis, external ophthalmoplegia, and no light perception. The left cornea was reasonably clear except for the area of infiltration around the original laceration, and, apart from some residual exudate around the pupil margin, the left anterior chamber was satisfactory. The antibiotic regimen was modified on receipt of the culture and sensitivity reports.

Enucleation of the right eye was performed on 30 August 1982 . The operation was virtually bloodless. The resolution of signs was rapid, and a prosthesis was fitted three weeks later.

The postoperative course was marked by temperature spikes that subsided within the week and by leucopenia. The vision of the left eye improved from perception of light to counting fingers at 2 feet $(60$ $\mathrm{cm})$. The cornea cleared except for scarring around the perforation site. There were anterior and posterior subcapsular lens opacities that progressed over the next two months. Repeated ultrasonography failed to show any evidence of an intraocular foreign body. A planned extracapsular cataract extraction was done on 22 November 1982. Convalescence on this occasion was uneventful.

The best recorded visual acuity on 10 February 1983 was $6 / 18$ with $+13 \cdot 0 /-2 \cdot 25$ axis $110^{\circ}$ and $N 8$ with a +3.0 addition. The fundus appeared normal. The limitation in distance acuity was due to the corneal scar that intruded on the pupil area nasally and to some thickening of the posterior lens capsule (Fig. 1). Pathological findings. Gram-positive bacilli and polymorphs were identified in smears of material

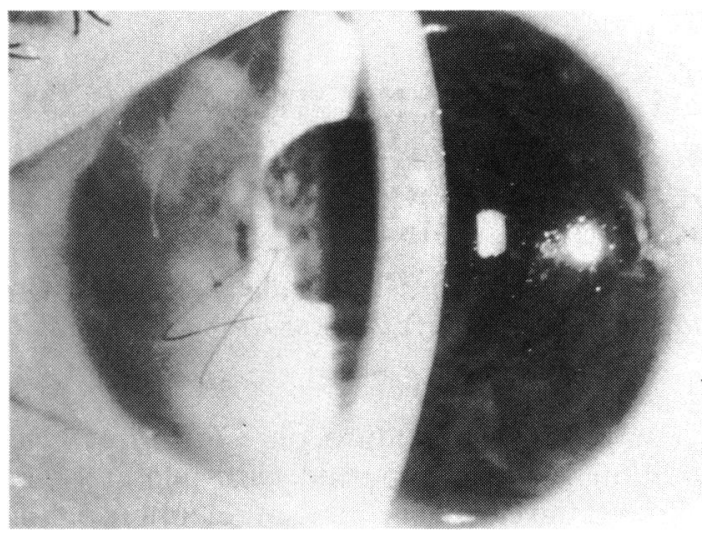

Fig. 1 Slit-lamp photograph of the anterior segment of the left eye following extracapsular cataract extraction. Best acuity $6 / 18, N 8$.

from both eyes, and Clostridium perfringens was cultured from each eye.

Histopathological examination of the enucleated right eye showed a panophthalmitis (Fig. 2). There was a heavy infiltrate of polymorphs in the anterior chamber, vitreous, subretinal space, choroid, and sclera. The retina was detached and partly necrotic. Very few Gram-positive bacilli were identified within the inflammatory exudate.

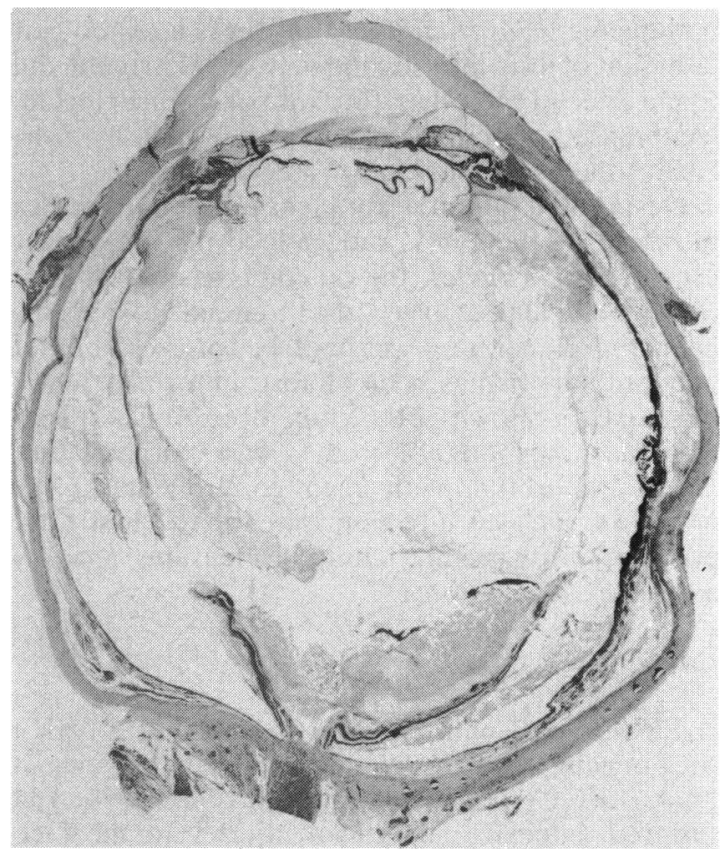

Fig. 2 Photomicrograph of histological section of the enucleated right eye. The retina is totally detached, and there is an acute inflammatory exudate through all coats of the eye. (Haematoxylin and eosin, $\times 3$ ). 


\section{Discussion}

SYNOPSIS OF PREVIOUS CASE REPORTS

The modern literature on gas gangrene of the eye was inaugurated by the French between 1904 and 1906. ${ }^{3-6}$ More than 20 years later Frederick Ridley could cite only five case reports. In a brief but masterful paper he described a single additional case and defined the clinical hallmarks of this disease. ${ }^{7}$ In 1936 Kluever and $\mathrm{O}^{\prime}$ Brien $^{\times}$added another single case and, in reviewing the literature, referred to gangrenous dacryocystitis. They conducted extensive laboratory and animal experiments on the causative organism from their case. As early as 1938 it was noted by Sidney Walker that ocular infection by Clostridium perfringens did not carry the same risk of mortality as was associated with contaminated limb wounds, nor the same frequency of occurrence."

The first instance of the use of antibiotics against clostridial ophthalmitis was contained in McGregor's report of the case of a maltster who presented with a five day history of severe pain in the right eye and grossly swollen lids. " Small incisions had been made in the outer third of both lids close to the orbital margins. Brown pus and bubbles were escaping from the wounds. The smell was foul. Sinus lavages were repeated over six weeks, then a radical antrostomy was performed. Staphylococcus aureus and Grampositive bacilli with filamentous forms, some resembling spores, were isolated. The patient was treated with antigas-gangrene serum and sulphathiazole. Fundus examination showed optic atrophy only. There was no perception of light in the eye.

The use of penicillin was first reported by Capus in $1946^{11}$ in an injury sustained after the explosion of a wooden military mine. The left eye at evisceration was found to contain an intraocular wooden foreign body and coffee coloured exudate, with gas of a characteristic odour.. Clostridium perfringens was isolated and cultured from this material. The right eye, though injured superficially, was not similarly infected. The author noted that clostridial infection had occurred despite the early use of penicillin and sulphadiazine.

By 1951, when Kennedy and Vogel ${ }^{12}$ added another civilian case of panophthalmitis due to Clostridium perfringens, the literature count had reached 28 . In their patient the inexorable progress of the panophthalmitis was interrupted by intensive systemic penicillin therapy, though the eventual outcome for the eye was evisceration 60 hours after injury.

In 1955 Robert Leavelle' reviewed the literature and added three new cases of gas gangrene panophthalmitis. He briefly described a fourth case (not panophthalmitis) - a massive penetrating wound of the globe with confirmed Clostridium perfringens contamination. He detailed 24 authors who between them had described 53 cases since 1904. Four characteristics were common to every instance of gas gangrene panophthalmitis: infection followed a perforating wound of the globe; despite any and all measures undertaken the infection progressed and destroyed all visual function; the infected globe was either eviscerated or enucleated, or the entire orbit exenterated; postoperative recovery was essentially uneventful and complete. In all cases the course was fulminating regardless of the magnitude of the original injury. The three cases of Lutz were the exception in not following such a course. ${ }^{13}$

The diagnosis was suspected clinically in several cases but was not established by laboratory means in any case until more than 48 hours after injury. The end result was the same in all cases-complete disorganisation of the visual function and the final necessity for removal of the destroyed tissues by surgical means. Exenteration was necessary in two cases.

Clostridium perfringens conjunctivitis was first described as a clinical entity in 1963 by Henkind and Fedukowicz. ${ }^{14}$ They reviewed the chronic unilateral Clostridium perfringens dacryocystitis followed by panopthalmitis as described by Beneditti, ${ }^{15}$ the three cases of gas infection of the cornea after gunshot wounds to the eye described Pringle, ${ }^{16}$ and the report of Clostridium perfringens contamination of the lashes without other evidence of infection.

Henkind and Fedukowicz reported on two patients, ${ }^{14}$ both severely ill, who were faecally incontinent. Though the conjunctivitis was of the moderate exudative type, multiple small haemorrhages were present; the entire process was confined to the lower fornices and adjacent bulbar conjunctiva. A culture of Clostridium perfringens obtained from one patient was used to prepare a suspension for experimental purposes. Conjunctivitis occurred in one of three guinea-pigs into which the suspension had been injected. In 1970 Levitt and Stam ${ }^{17}$ described the case of a young child injured by a splinter of wood. Therapy resulted in a retained globe with traumatic cataract and perception of light.

Bristow et al. ${ }^{18}$ wrote from South Africa and contributed case 62 in 1971. This was the first recorded case in which hyperbaric oxygen was used as an adjuvant to therapy. They suggested that such therapy was indicated only when there is clinical evidence of extraocular extension of the gas gangrene. The disease was again cut short by evisceration. In the same issue of the journal case 63 was reported from England, ${ }^{19}$ another fulminant panophthalmitis where a ring corneal abscess developed. These two papers evoked an editorial comment ${ }^{20}$ which ended 
with the ominous statement that 'so far, no eye with proved gas gangrene panophthalmitis has ever been saved by antibiotic treatment alone.'

The contrast in systemic complications of general versus ocular clostridial infections was highlighted by a series of papers in 1973. ${ }^{21-24}$ Involvement of the eye and orbit by gas gangrene was not discussed and has not been recorded in Australia previously.

In 1974 Frantz et al. ${ }^{25}$ reported the only known case of Clostridium perfringens endophthalmitis produced by endogenous spread. The patient presented with simultaneous abdominal pain and loss of vision. At operation a perforated gangrenous gall bladder was found. The patient died and at necropsy both eyes were enucleated. The left eye was the seat of clostridial endophthalmitis. Detailed histological findings are given in the paper. After the single case of Kessler et al. in 1976 from Switzerland ${ }^{26}$ the present report becomes the 67 th to be presented.

\section{COMMENTS}

The literature of ophthalmic gas gangrene infections contains many single case reports that are depressingly repetitive in the final outcome, despite a variety of therapeutic initiatives. The classical course of this infection was succinctly summarised by Duke-Elder ${ }^{27}$ (Table 1). He stated, 'In every case, usually within 24 hours after injury, a characteristic fulminating panophthalmitis develops with six distinctive clinical features, the recognition of which is important because of the necessity for urgent and radical treatment.'

One would be reluctant to add a further case report were it not for several noteworthy features, the fore-
Table 1 Signs and symptoms of gas gangrene panophthalmitis

\author{
1 Rapid onset with unusually severe pain \\ 2 Brawny swelling of cyclids \\ 3 Early rise in ocular tension \\ 4 Blood of a thin coffec coloured discharge \\ 5 Gas bubbles in anterior chamber \\ 6 Rapid development of total amaurosis
}

most of which is a final visual acuity of $6 / 18, N 8$ in the left eye. Although survival of the globe with optic atrophy ${ }^{10}$ and with dense cataract and perception of light ${ }^{17}$ has been reported, this would seem to be the first case of bilateral infection in which the clinical course of the two eyes is vividly contrasted. The classical outcome on the right side, with amaurosis and hypopyon within 24 hours of sustaining an intravitreal foreign body, reinforces the justly feared devastation due to an established Clostridium perfringens infection. The left side, with a confirmed intracameral infection and gas bubble, was treated by vitrectomy instrumentation and antibiotics. The posterior pole was observed to be normal after the removal of the toxic cataract. The traumatic corneal leucoma and wrinkling of the posterior lens capsule were of sufficient degree to account for the reduction in the final visual acuity to $6 / 18, N 8$.

The involvement of both orbits showed differing clinical patterns - the right, secondary to the clostridial panophthalmitis; the left, by direct penetration of soil. The right orbit was not involved in the primary trauma, the site of penetration being several millimetres posterior to the limbus. Within 24
Fig. 3 Histological section from the enucleated right eye. The lens capsule (asterisk) is enclosed on both sides by polymorphs.

(Haematoxylin and eosin, $\times 243$ ).

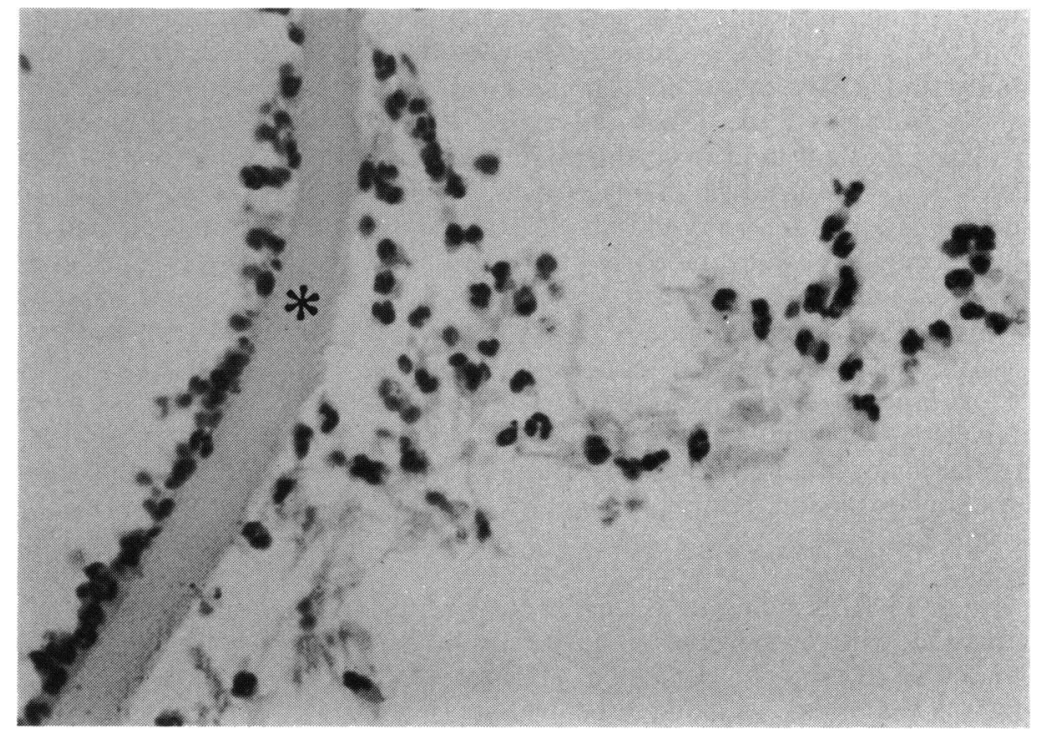




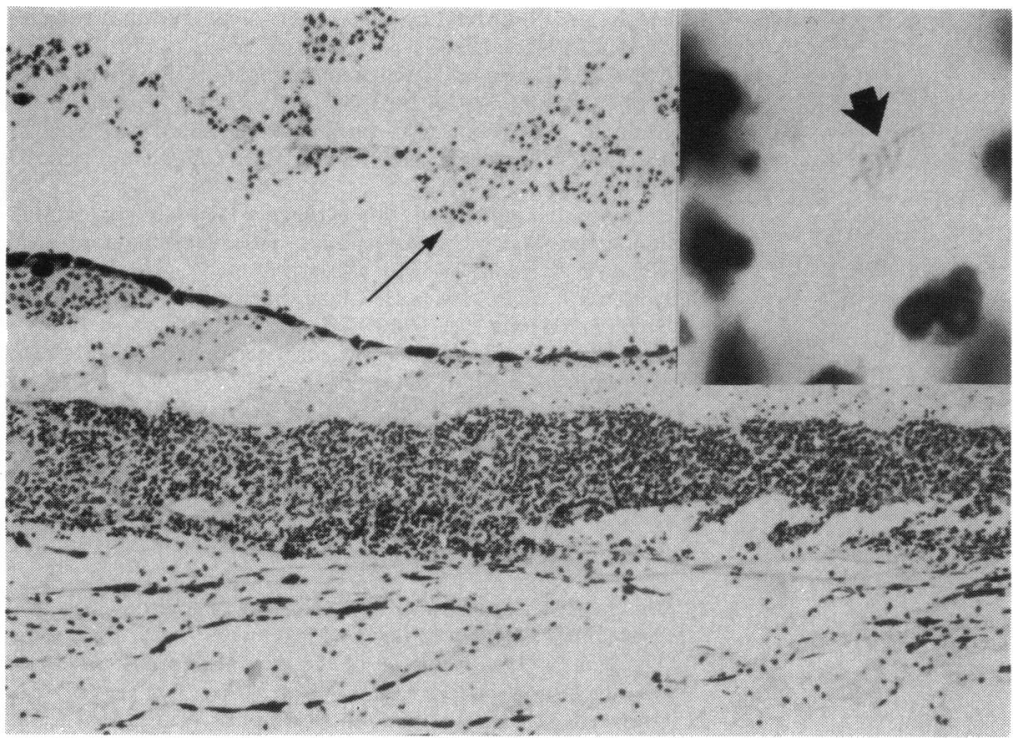

Fig. 4 Photomicrograph of the choroid from the enucleated right eye. There is a heavy infiltrate of polymorphs in the choroid. There are moderate numbers of polymorphs in the subretinal space (long arrow). (Haematoxylin and eosin, $\times 61$ ) Inset: Gram-positive bacilli (short arrow) are identified within the inflammatory exudate. (Gram stain, oil immersion, $\times 608$ ).

hours there were signs of orbital cellulitis with a marked proptosis accompanying the intraocular suppuration. The orbital cellulitis was almost certainly part of the panophthalmitis and not the result of a separate inoculation. Histopathological examination of the enucleated eye confirmed a panophthalmitis with only occasional identifiable microorganisms. This is consistent with previous reports, ${ }^{1}$ is where scanty organisms were found in the affected globe despite severe disruption of the contents. These findings highlight the powerful effect of the exotoxins produced by Clostridium perfringens, which not only cause rapid destruction of the lens, as seen in the present case (Fig. 3), retina, and choroid (Fig. 4), but also affect the extraocular tissues.

The degree of proptosis of the right globe was marked. In contrast there was minimal swelling of the left orbit, despite deep tracts into it, contaminated by soil containing Clostridium perfringens. The difference in the degree of tissue swelling was probably attributable to the effective decompression of the left orbital septum by the explosive penetrations.

With regard to management the significant factor that differs from all earlier reports is the use of vitrectomy instrumentation. Because of early opacification in the media of the right eye its application was limited to a vitreous biopsy on that side. However, in the left eye the removal of the fibrinenmeshed mud from the iris and inferior angle was dramatic both in execution and effect. Culture of this material confirmed the presence of Clostridium perfringens, and the gas bubble attested to its activity. While the useful visual outcome may be attributed to the removal of the mud and inoculum of organisms from the anterior chamber, one must be cautious in according the success entirely to surgical intervention.

Clostridium perfringens requires specific conditions for fulminant growth and the production of exotoxins. Von Sallman,,$^{2 k}$ using an experimental model to test antibiotic sensitivities, could produce clostridial panophthalmitis only by inoculation of organisms deep into the nucleus of the lens. After six hours penicillin could not arrest the bacterial growth. By contrast Staphylococcus aureus and Streptococcus pneumoniae would reliably induce panophthalmitis after inoculation into the anterior chamber after only a few superficial scratches were made on the anterior surface of the lens. Von Sallman's work highlighted the importance of the low redox potential necessary for the growth of Clostridium perfringens. In the eye this is found in the avascular tissue of the lens and vitreous. Owing to the vascularity of the iris the anterior chamber has a higher oxygen level than the vitreous or lens and is less favourable to the growth of anaerobes. With regard to the case presented here the successful culture of the organisms some 24 hours after trauma, and the production of the gas bubble, confirms that the anterior chamber will support the growth of Clostridium perfringens in the presence of debris.

The successful outcome on the left side invites speculation that early vitrectomy with removal of all foreign material may have altered the outcome for the right eye. While simple removal (by magnet) of a foreign body, even within six hours of trauma, has not prevented panophthalmitis, ${ }^{29}$ the early removal of the avascular vitreous would theoretically reduce the size of the inoculum, remove the majority of the 
avascular tissue, and irrigate the vitreous cavity with oxygenated fluid.

The major obstacle to implementation of such management is the fact that microbiological confirmation may not be available for 24 hours or more. Simple foreign body removal is all that is warranted in many cases of penetrating injuries, and surgeons are rightly loath to perform acute vitrectomy unless certain of its benefit. However, the catastrophic outcome of established clostridial panophthalmitis brooks no delay for traditional microbiological culture methods. Therefore, cases of military and civilian injuries should be regarded as being at just as high a risk of clostridial infection in the eye as in the limbs or abdomen. They should be assessed for the potential benefit of debridement of avascular and necrotic tissue, which, in the eye, would involve total vitrectomy and also lensectomy if the lens were involved.

\section{Reférences}

1 Leavelle RB. Gas gangrene panophthalmitis. Arch Ophthalmol 1955; 53: 634-42.

2 McDonel JL. Clostridium perfringens toxins (Type A, B, C, D and E). Pharmacol Ther (B) 1980; 10: 617-55.

3 Chaillous $\mathbf{J}$. Infection traumatique du globe oculairc par un microbe anacrobic (Bacillus perfringens). Rec Ophtalmol 1904; 26: $678-80$.

4 Chaillous J. Deux cas d'infection traumatique duc globe oculaire par un microbe anaerobic (Bacillus perfringens). Ann Oculist (Paris) 1905; 134: 115.

5 Darier A. Panophtalmic et Bacillus perfringens. Clinique Ophtalmologique 1905; 11: 266.

6 Darier A. Panophtalmic gazeuse et bacillus perfringens. Clinique Ophtalmologique 1906; 12: 227-9.

7 Ridlcy F. Gas gangrene panophthalmitis. Trans Ophthalmol Soc UK 1929; 49: 221-5.

8 Kluever HC, O'Brien CS. Panophthalmitis due to Clostridium welchii. Arch Ophthalmol 1936; 15: 1088-93.

9 Walker S. Prognosis of Bacillus welchii panophthalmitis. Arch Ophthalmol 1938; 19: 406-8.
10 McGregor IS. Orbital cellulitis from gas producing organisms. Br Med J 1942; i: 292-3.

11 Capus B. Clostridium welchii panophthalmitis. Report of a case. Arch Ophthalmol 1946; 36: 226-8.

12 Kennedy RJ, Vogel AW. Intraocular infection with the gasforming bacillus Clostridium welchii. Arch Ophthalmol 1951; 45: 528-30.

13 Lutz A. Über einige Falle von ektogener Panophthalmic (infektionen mit Pneumococcus subtilis und anacrobionten). Klin Monatsbl Augenheilkd 1910; 48: 31.

14 Henkind P, Fedukowicz $\mathrm{H}$. Clostridium welchii conjunctivitis. Arch Ophthalmol 1963; 70: 791-5.

15 Benedetti A. Panoftalmite a bacillo 'perfringens.' Clin Oculist (Palermo) 1970; 8: 3013.

16 Pringle JA. Three cases of gas infection of the cornea following gunshot wounds to the cyc. BrJ Ophthalmol 1919; 3: 110.

17 Levitt JM, Stam J. Clostridial perfringens panophthalmitis. Arch Ophthalmol 1970; 84: 227-8.

18 Bristow JH, Kassar B, Sevel D. Gas gangrene panophthalmitis treated with hyperbaric oxygen. Br J Ophthalmol 1971; 55: 13942.

19 Bhargava SK, Chopdar A. Gas gangrene panophthalmitis. Br J Ophthalmol 1971; 55: 136-8.

20 Anonymous. Gas gangrene of the cyc. (Editorial). Br Med J 1971; ii: 419-20.

21 Unsworth IP. Gas gangrene in New South Wales. Med J Aust 1973 ; i: $1077-80$.

22 Shaw J, Vellar ID, Vellar D. Clostridial (gas gangrene) infection in a general hospital. Med J Aust 1973; i: 1080-7.

23 McKinnon D, McDonald P. Gas gangrenc-a ten-ycar survey from the Royal Adclaide Hospital. Med J Aust 1973; i: 1087-90.

24 Deveridge RJ, Unsworth IP. Gas gangrene. Med J Aust 1973; i: $1106-9$.

25 Frantz JF, Lemp MA, Font RL, Stone R, Eisner E. Acutc endogenous panophthalmitis caused by Clostridium perfringens. Am J Ophthalmol 1974; 78: 295-303.

26 Kessler S, Schmid E, Pagon S. Panophthalmic durch Gasbranderreger. Klin Monatsbl Augenheilkd 1976; 168: 134-7.

27 Dukc-Elder S. System of ophthalmology. London: Kimpton, 1972; 14: 405-10.

28 von Sallman L. Penicillin and sulfadiazine in the treatment of experimental intraocular infections with Staphylococcus aurcus and Clostridium welchii. Arch Ophthalmol 1944; 31: 54-63.

29 Walsh T. Clostridial ocular infections. Case report of gas gangrene panophthalmitis. Br J Ophthalmol 1965; 49: 472-7. 